\title{
ASSESSMENT OF CARDIOVASCULAR RISK IN PATIENTS WITH TYPE 2 DIABETES MELLITUS AND ASSOCIATED OBESITY AND WAYS OF ITS CORRECTION
}

DOI: 10.36740/WLek202104135

\author{
Taras I. Griadil', Ivan V. Chopey' ${ }^{1}$ Ksenia I. Chubirko' , Mykhaylo M. Hechko' ${ }^{1}$, Wael Rumaneh ${ }^{2}$ \\ 'STATE HIGHER EDUCATIONAL ESTABLISHMENT «UZHHOROD NATIONAL UNIVERSITY», UZHHOROD, UKRAINE \\ 2SUMY STATE UNIVERSITY, SUMY, UKRAINE
}

\begin{abstract}
The aim: To analyze and calculate CVR in patients with T2DM and concomitant obesity.

Materials and methods: The selection of patients was carried out based on the Uzhhorod District Clinical Hospital, in the period from November 2016 to January 2020 . All patients were divided into 3 groups: 1 ( $n=93$ ) with T2DM and concomitant obesity, $2(n=87)$ with T2DM, $3(n=39)$ with obesity. The treatment period lasted 1 year and included dosed exercise for at least 30 minutes per day and dietary recommendations. Patients in groups 1 and 2 received metformin $850 \mathrm{mg}$ twice daily in combination with dapagliflozin $10 \mathrm{mg}$ once daily. (VR was determined at the time of enrollment and after 1 year of treatment using: American College of Cardiology / American Heart Association Guideline on the Assessment of Cardiovascular Risk (2013) (ASCVD Risk) and Framingham Risk Score (FRS).

Results: The data obtained as a result of the study revealed the highest CVR in patients of group 1, in contrast to group 2 and 3 ( $p<0.05$ ). After 1 year of complex treatment, CVR indicators were statistically significantly reduced in all experimental groups $(p<0.05)$.

Conclusions: Determining CVR parameters and exposure to them within 10 years can remove unwanted cardiovascular complications.
\end{abstract}

KEY WORDS: type 2 diabetes mellitus, obesity, treatment, diagnostics, dapaglifloflozin, cardiovascular risk

Wiad Lek. 2021;74(4):998-1002

\section{INTRODUCTION}

Type 2 diabetes mellitus (T2DM) is characterized by multivariate systemic complications that significantly impair the quality of life of patients and reduce their life expectancy [1].

T2DM is considered an absolute risk factor for atherosclerosis [2]. The basis of this pathological process is a violation of carbohydrate metabolism, one of its manifestations is hyperglycemia, which leads to changes in the lipid spectrum of blood (deviate from normal levels of total cholesterol, triglycerides, high and low-density lipoprotein cholesterol) [3]. In the long run, lipid-protein glycan complexes are deposited in blood vessels, leading to the development of diabetic micro- or macroangiopathy $[3,4]$.

Therefore, chronic microvascular complications of T2DM include nephropathy, erectile dysfunction, cataracts, and retinopathy, the consequences of which are blindness, neuropathy with a distant complication - amputation of limbs and others [5]. Instead, chronic macrovascular complications of T2DM include atherosclerotic lesions of the lower extremities resulting in the diabetic foot, which in turn may be complicated by the need for amputation of limbs, stroke, coronary heart disease (CHD) with a possible course: angina and/or myocardial infarction (MI) and others [6].

According to studies, patients with T2DM are overweight and obese [7]. Obesity from a pathophysiological point of view is considered as a chronic inflammatory process that has a complex and detrimental effect on the whole body in general, provoking the development of hypertension, impaired glucose metabolism, vascular damage (acceleration of atherosclerosis and its consequences), contributing to the development of cardiovascular complications (MI, stroke, etc.), infertility, oncology, obstructive sleep apnea syndrome, etc. $[7,8]$. Several clinical studies have shown that anthropometric parameters are closely related to the risk of cardiovascular disease (CVD): body mass index (BMI), waist circumference (WC), hip circumference (HC), and waist-to-hip ratio (WHR) [9]. Each additional kilogram of weight directly affects the final value of blood pressure, while the increase in waist WC, HC, WHR is closely related to the predictor of CVD [10]. That is why obesity is considered an additional factor of cardiovascular risk (CVR).

Quite often there is a comorbid combination of T2DM and hypertension, which significantly accelerates the pathological process of vascular endothelial damage, both metabolic pathogenesis and changes in vascular pressure, which exacerbates the development of vascular complications of the kidneys and heart, brain, peripheral vessels of the lower extremities [11]. Thus, the risk of CHD, stroke and dozens of times, vision loss, amputation of the lower extremities, and other complications increases several times [11]. 
Cardiovascular complications as a consequence of T2DM can be prevented and in some cases removed by determining the patient's CVR, know the prognosis for the patient and make a comprehensive correction based on individual needs.

From a practical point of view, various methods of assessing CVR are widely used, in particular in the 10 -year perspective: $Q$ risk 2 score calculator and Modified Q risk 2, PROCAM score, The Framingham risk score (FRS), SCORE, American College of Cardiology / American Heart Association Guideline on the Assessment of Cardiovascular Risk (2013) (ASCVD Risk) [12-16].

SCORE, FRS, ASCVD Risk remain the most widely used in routine clinical practice to assess CVR. Thus, the SCORE scale, created based on the results of clinical trials involving more than 250,000 patients, allows us to assess the risk of fatal cardiovascular events (CVE) in the next 10 years. $[13,15,16]$.

American College of Cardiology / American Heart Association Guideline on the Assessment of Cardiovascular Risk (2013) (ASCVD Risk) is categorized as low-risk $(<5 \%)$, borderline risk ( $5 \%$ to $7.4 \%$ ), intermediate-risk ( $7.5 \%$ to $19.9 \%)$, high risk ( $\geq 20 \%)$ of 10 -year risk of MI and/or stroke $[15,17]$.

The Framingham Risk Score (FRS) for hard CHD which evaluates the ten-year risk of CVD (CHD, stroke, chronic heart failure, heart death) in percentage was calculated by total points was classified as low risk $(<10 \%)$, intermediate-risk (10-20\%), and high risk (>20\%) [14, 18].

CVD is one of the leading causes of global mortality and one of the most common causes of disability. CVD prevalence increased from 271 million in 1990 to 523 million in 2019 and continues to rise, while the number of CVD deaths increased from 12.1 million in 1990 to 18.6 million in 2019 [19].

Annually increasing costs associated with CVD, particularly so in the USA alone as of 2015 spent 126 billion dollars and are projected to grow more than 2.5 times to 309 billion dollars in 2035 [20].

\section{THE AIM}

Analyze and calculate CVR in patients with T2DM and concomitant obesity and comprehensively influence the obtained CVR, reducing the 10-year risk of CVE.

\section{MATERIALS AND METHODS}

The selection of patients took place based on the therapeutic department of the Municipal Non-Profit Enterprise "Uzhhorod District Clinical Hospital of Uzhhorod District Council of Transcarpathian region", and at outpatient treatment department of the therapy and the family medicine of the Faculty of Postgraduate and Pre-University Education of the State Higher Educational Establishment «Uzhhorod National University» in the period from November 2016 to January 2020. In the course of the study, 93 people with T2DM and concomitant obesity, who were included in the 1st group, were examined and 126 medical cards of an inpatient with a diagnosis of T2DM and ambulatory card data included in the 2nd group were retrospectively analyzed. group ( $n=87)$, while group 3 included patients diagnosed with obesity $(n=39)$. The treatment period in patients lasted 1 year and included dosed exercise lasting at least 30 minutes a day and dietary recommendations, also patients in groups 1 and 2 received metformin 850 mg 2 times a day in combination with dapagliflozin 10 mg 1 time per day.

All subjects were examined: general clinical examination, anthropometric measurements, calculation of BMI, WC, HC, WHR, glycosylated hemoglobin (HbAlc), lipid profile, collection of medical and social history, and bad habits. All patients in the study were additionally interviewed about the correctness of dietary and treatment recommendations.

CVR was determined at the time of inclusion in the study and after 1 year of treatment. The following calculators were used to calculate the CVR: 1) American College of Cardiology/American Heart Association Guideline on the Assessment of Cardiovascular Risk (2013) (ASCVD Risk) is categorized as low-risk $(<5 \%)$, borderline risk (5\% to $7.4 \%$ ), Intermediate risk (7.5\% to $19.9 \%$ ), high risk $(\geq 20 \%)$ of 10 -year risk of $\mathrm{MI}$ and/or stroke $[15,17]$ and 2) The Framingham Risk Score (FRS) for hard CHD which evaluates the ten-year risk of CVD (CHD, stroke, chronic heart failure, heart death) in percentage was calculated by total points was classified as low risk $(<10 \%)$, intermediate-risk (10-20\%), and high risk (>20\%) $[14,18]$.

Additionally, to find the potential risk for patients with T2DM, a bibliographic search was performed on the keywords "treatment of type 2 diabetes mellitus", "type 2 diabetes mellitus", "dapagliflozin", "metformin", "risk factors", "cardiovascular risk" in the following databases PubMed, MEDLINE, Web of Science, Cochrane Library, Google Akademy.

The diagnosis criteria for T2DM were established based on the American Diabetes Association. The diagnosis of obesity was established by measuring $\mathrm{BMI} \geq 30 \mathrm{~kg} / \mathrm{m}^{2}$, and the value of BMI was assessed by the degree of obesity.

The statistical processing of the research results was performed using the program software International Business Machines Corporation Statistical Package for the Social Sciences Statistics. The statistical analysis of the materials, the summary, and also the summary of the conclusions were made by the method of the variation statistics, taking into account the average values (mod, median, arithmetic mean) and the average error $(\mathrm{M} \pm \mathrm{m})$, with the estimation of the reliability of the values by the Student's t-criterion, as well as with the determination of the correlation coefficient using the Pearson's paired method to identify the relationships between the obtained indicators. For the minimum threshold of probability, the values $\mathrm{p}<0.05$ were taken.

The whole set of the surveys were by the Articles 3,44 of the Fundamentals of the Legislation of Ukraine on Healthcare, the Articles 7, 8 of the Law of Ukraine "On Medicines", the Law of Ukraine "On Protection of Personal Data", taking into account the requirements of the European Parliament and 
Table I. Anthropometrical parameters in group 1, 2 and 3.

\begin{tabular}{cccc}
\hline Parameter & \multicolumn{3}{c}{ Group } \\
\cline { 2 - 4 } & $\begin{array}{c}\text { Group 1 } \\
(\mathbf{n = 9 3 )}\end{array}$ & $\begin{array}{c}\text { Group 2 } \\
(\mathbf{n = 8 7})\end{array}$ & $\begin{array}{c}\text { Group 3 } \\
\text { (n=39) }\end{array}$ \\
\hline $\mathrm{BMI}^{\mathrm{B}}\left(\mathrm{kg} / \mathrm{m}^{2}\right)$ & $32,57 \pm 0,18$ & $28,74 \pm 0,21$ & $32,24 \pm 0,32$ \\
\hline $\mathrm{WC}^{\mathrm{B}}(\mathrm{cm})$ & $110,59 \pm 1,35$ & $88,41 \pm 1,17$ & $108,62 \pm 1,19$ \\
\hline $\mathrm{HC}^{\mathrm{B}}(\mathrm{cm})$ & $103,8 \pm 0,92$ & $92,6 \pm 1,04$ & $105,17 \pm 0,89$ \\
\hline $\mathrm{WHR}^{\mathrm{B}}$ & $1,07 \pm 0,01$ & $0,95 \pm 0,01$ & $1,03 \pm 0,01$ \\
\hline $\mathrm{BMI}{ }^{\mathrm{AT}}\left(\mathrm{kg} / \mathrm{m}^{2}\right)$ & $31,34 \pm 0,22$ & $27,32 \pm 0,17^{*}$ & $30,67 \pm 0,26 \#$ \\
\hline $\mathrm{WC}^{\mathrm{AT}}(\mathrm{cm})$ & $104,67 \pm 1,18$ & $85,72 \pm 1,12^{*}$ & $103,70 \pm 1,08 \#$ \\
\hline $\mathrm{HC} C^{\mathrm{AT}}(\mathrm{cm})$ & $101,2 \pm 1,04$ & $90,3 \pm 1,19^{*}$ & $102,21 \pm 0,89 \#$ \\
\hline $\mathrm{WHR}^{\mathrm{AT}}$ & $1,03 \pm 0,01$ & $0,95 \pm 0,01^{*}$ & $1,01 \pm 0,01 \#$
\end{tabular}

Note: $B$ - patient data at the beginning of the study; AT - patient data after 12 months of treatment and follow-up; BMI - Body Mass Index; WC - Waist circumference; HC - the hip circumference; WHR - waist-to-hip ratio; ${ }^{*}$ - statistically significant difference when comparing the indicators between the respective groups 1 and $2(p<0.05)$; \# - a statistically significant difference when comparing the indicators between the respective groups 1 and $3(p<0.05)$.

Table II. FPG and HbA1C levels

\begin{tabular}{cccc}
\hline Parameter & \multicolumn{3}{c}{ Group } \\
\cline { 2 - 4 } & $\begin{array}{c}\text { Group 1 } \\
(\mathbf{n = 9 3 )}\end{array}$ & $\begin{array}{c}\text { Group 2 } \\
(\mathbf{n = 8 7 )}\end{array}$ & $\begin{array}{c}\text { Group 3 } \\
(\mathbf{n = 3 9 )}\end{array}$ \\
\hline FPG $^{\text {B }}$ & $9,21 \pm 0,17$ & $8,96 \pm 0,11$ & $5,81 \pm 0,12$ \\
\hline${\text { HbA1C }(\%))^{\text {B }}}^{\text {FPG }}{ }^{\text {AT }}$ & $8,3 \pm 0,05$ & $8,12 \pm 0,08$ & $5,77 \pm 0,06$ \\
\hline${\text { HbA1C }(\%)^{\text {AT }}}^{7,21 \pm 0,08}$ & $6,69 \pm 0,12^{*}$ & $5,51 \pm 0,15 \#$ \\
\hline
\end{tabular}

Note: $B$ - patient data at the beginning of the study; AT - patient data after 12 months of treatment and follow-up; FPG - Fasting plasma glucose; $\mathrm{HbA1C}$ - glycated hemoglobin; normal values of FPG - 3.3-5.5 mmol/l; normal values of $\mathrm{HbA1C}-4-6.4 \%$; ${ }^{*}$ - statistically significant difference when comparing the indicators between the respective groups 1 and 2 $(p<0.05)$; \# - a statistically significant difference when comparing the indicators between the respective groups 1 and $3(p<0.05)$.

Council Directives 2001/20/ EU of April 4, 2001, 2001/83/ EU of November 6, 2001, the Decisions of the European Parliament and of the Council 1901/2006 of December 12, 2006, and 1902/2006 of December 20, 2006, ICH GCP, International Ethical Principles for Biomedical human-related research and physician code of conduct, and order in the Ministry of Health of Ukraine No. 690 of September 23, 2009, as well as the order of the Ministry of Health of Ukraine No. 1118 of December 21,2012 , the unified clinical protocol of the primary and the secondary (specialized) medical care of T2DM.

\section{RESULTS}

Those included in this study were $\geq 40$ years old. The mean age of the patients in the 1st group was $51.3 \pm 1.2$ years, compared with $52.7 \pm 1.1$ years of the patients in the 2 nd group, whereas in group 3 the age of patients was $54.5 \pm 1.2$ years. The ratio of men and women in group 1 was 32 men and 61 women against 34 men and 53 women in group 2 and 18 men and 21 women in group 3 . The mean duration of T2DM in group 1 was $14.8 \pm 3.2$ years, as opposed to $13.5 \pm 1.6$ years in group 2 .

Currently, the status of a smoker was in group $1-29$ people, group $2-17$ people, and group $3-22$ people. Instead, in the past, there were additionally smokers in group $1-13$ people, in group $2-8$ people, and group $3-6$ people. Hypertensive disease and received treatment for it: in group $1-35$ people, in group $2-21$ people, and group $3-27$ people. MI was suffered in the past: in group $1-11$ people, in group $2-7$ people, and group $3-4$ people. Instead, during 1 year of observation, MI was additionally transferred: in group $1-3$ persons, in group $2-1$ person, and group $3-2$ persons. Stroke was suffered in the past: in group $1-8$ people, in group $2-3$ people, and group $3-1$ person. Instead, during 1 year of follow-up, an additional stroke: in group $1-2$ people, in group $2-3$ people, and in group $3-2$ people. Aspirin therapy was taken: in group $1-36$ people, in group $2-15$ people, and group $3-11$ people. Statins were taken: in group $1-24$ people, in group $2-11$ people, and in group $3-7$ people.

At the beginning of the study, according to the obtained data on BMI: in group $1-58$ people were with grade I obesity, 23 people had grade II obesity, 11 people had grade III obesity; in group II - 53 people were overweight, while 34 people were normal weight; in group 3 - 25 people were with I degree of obesity, 11 people had II degree of obesity and 3 people with obesity of III degree.

According to the data obtained as a result of the measuring anthropometric parameters of the patients of the 1st and the 2 nd group and 1 st and the 3 rd group at the beginning of the study, no statistically significant difference was found between them $(\mathrm{p}>0.05)$. The BMI at the beginning of the study in group 1 was $32,57 \pm 0,18 \mathrm{~kg} / \mathrm{m} 2$, respectively $28,74 \pm 0,21 \mathrm{~kg} / \mathrm{m} 2$ in group 2 and $32,24 \pm 0,32 \mathrm{~kg} / \mathrm{m} 2$ in group 3 . The $\mathrm{WC}$ index in group 1 at the beginning of the study was $110,59 \pm 1,35 \mathrm{~cm}$, respectively $88,41 \pm 1,17 \mathrm{~cm}$ in group 2, and $108,62 \pm 1,19 \mathrm{~cm}$ in group 3 . WHR in the group 1 was $1,07 \pm 0,01$ and $0,95 \pm 0,01$, respectively in the group 2 and $1,03 \pm 0,01 \mathrm{~cm}$ in the group 3 .

It is noteworthy that 12 months after the course of comprehensive treatment and observation, between anthropometric indicators of patients of the 1st and 2nd group there was a statistically significant difference, the same dynamics were also observed when comparing the 1 st and 3rd groups $(\mathrm{p}<0.05)$.

If at the beginning of the study in group $1 \mathrm{HbA1C}$ was $8.3 \pm 0.05 \%$, then after 12 months of complex treatment and observation $7.51 \pm 0.03 \%$, against the response of $8.12 \pm 0.08 \%$ and $6.45 \pm 0.04 \%$, respectively, in the second group. In contrast, in patients of group 3 before and after 12 months of complex treatment and observation, indicators within the norm of $\mathrm{HbA1C}$ were observed $-5.77 \pm 0.06 \%$ and $5.49 \pm 0.03 \%$, respectively. According to the obtained laboratory data of FPG and HbA1C, in patients of the 1st and 2 nd groups and the 1 st and 3 rd groups at the begin- 
Table III. Assessment of CVR on the American College of Cardiology/ American Heart Association Guideline on the Assessment of Cardiovascular Risk (2013) (ASCVD Risk)

\begin{tabular}{cccc}
\hline \multirow{2}{*}{ Parameter } & \multicolumn{3}{c}{ Group } \\
\cline { 2 - 4 } & $\begin{array}{c}\text { Group 1 } \\
(\mathbf{n = 9 3 )}\end{array}$ & $\begin{array}{c}\text { Group 2 } \\
\text { (n=87) }\end{array}$ & $\begin{array}{c}\text { Group 3 } \\
\text { (n=39) }\end{array}$ \\
\hline ASCVD Risk (\%) ${ }^{\text {B }}$ & $12,7 \pm 0,1$ & $11,8 \pm 0,2$ & $6,8 \pm 0,2$ \\
\hline ASCVD Risk (\%) ${ }^{\text {AT }}$ & $9,5 \pm 0,1$ & $9,2 \pm 0,3^{*}$ & $6,4 \pm 0,2 \#$
\end{tabular}

Note: B - patient data at the beginning of the study; AT - patient data after 12 months of treatment and follow-up; CVR - cardiovascular risk; ASCVD Risk - assessment of cardiovascular risk; ASCVD Risk is categorized as low-risk $(<5 \%)$, borderline risk ( $5 \%$ to $7.4 \%)$, intermediate-risk $(7.5 \%$ to $19.9 \%)$, high risk ( $\geq 20 \%)$ of 10 -year risk of myocardial infarction and/or stroke; ${ }^{*}$ - statistically significant difference when comparing the indicators between the respective groups 1 and $2(p<0.05)$; \# - a statistically significant difference when comparing the indicators between the respective groups 1 and $3(p<0.05)$.

Table IV. Assessment of CVR on the Framingham Risk Score (FRS)

\begin{tabular}{cccc}
\hline Parameter & \multicolumn{3}{c}{ Group } \\
\cline { 2 - 4 } & $\begin{array}{c}\text { Group 1 } \\
\text { (n=93) }\end{array}$ & $\begin{array}{c}\text { Group 2 } \\
\text { (n=87) }\end{array}$ & $\begin{array}{c}\text { Group 3 } \\
\text { (n=39) }\end{array}$ \\
\hline FRS (\%) ${ }^{\text {B }}$ & $24,6 \pm 0,4$ & $18,5 \pm 0,3$ & $14,8 \pm 0,5$ \\
\hline FRS (\%) ${ }^{\text {AT }}$ & $21,5 \pm 0,4$ & $16,1 \pm 0,4^{*}$ & $12,3 \pm 0,2 \#$ \\
\hline
\end{tabular}

Note: B- patient data at the beginning of the study; AT - patient data after 12 months of treatment and follow-up; FRS - Framingham Risk Score; FRS was classified as low risk $(<10 \%)$, intermediate-risk (10-20\%), and high risk (>20\%) of ten-year risk cardiovascular disease; ${ }^{*}$ - statistically significant difference when comparing the indicators between the respective groups 1 and $2(p<0.05)$; $\#$ - a statistically significant difference when comparing the indicators between the respective groups 1 and $3(p<0.05)$.

ning of the study, no statistically significant difference was found between them $(p>0.05)$. Analyzing the biochemical parameters of the blood, namely the metabolism of hydrocarbons, there is a tendency to reduce the level of fasting plasma glucose (FPG) and $\mathrm{HbA} 1 \mathrm{C}$ in groups 1 and 2 . There was a statistically significant difference between FPG and $\mathrm{HbA} 1 \mathrm{C}$ in patients of groups 1 and 2 and groups 1 and 3 after 12 months of study $(\mathrm{p}<0.05)$.

In all study groups, at the beginning of the study, there was an increased level of triglycerides, a decrease in high-density lipoprotein, and an increase in low-density lipoprotein. The level of triglycerides slightly decreased after treatment, compared with a baseline before treatment, but was still extremely high, a statistically significant difference between patients 1 and 2 groups and between patients 1 and 3 groups was not observed $(\mathrm{p}>0.05)$. In groups 1 and 2 at the beginning of the study, there was an increase in the concentration of apolipoprotein B over $120 \mathrm{mg} / \mathrm{dl}$, while in groups 3 this figure was within normal limits. Targets of the lipid profile in the experimental groups after the course of treatment were not achieved.

The other biochemical parameters obtained at different stages of the study did not reveal the statistically significant changes in the indicators of the groups 1 and 2 and 1 and 3 ( $p>0.05$ ).
At the beginning of treatment, ASCVD Risk in patients of group 1 was $12.7 \pm 0.1 \%$, group $2-11.8 \pm 0.2 \%$, and group $36.8 \pm 0.2 \%$, respectively. At the end of treatment, ASCVD Risk in patients of group 1 was $9.5 \pm 0.1 \%$, group $2-9.2 \pm 0.3 \%$, and group 3 , respectively, $6.4 \pm 0.2 \%$. There was a statistically significant difference between ASCVD Risk, between patients in groups 1 and 2 and groups 1 and 3 after 12 months of study $(\mathrm{p}<0.05)$.

At the beginning of treatment, FRS in patients of group 1 was $24.6 \pm 0.4 \%$, group $2-18.5 \pm 0.3 \%$, and group $314.8 \pm 0.5 \%$, respectively. At the end of FRS treatment in patients of the 1 st group $21.5 \pm 0.4 \%$, the 2 nd group $16.1 \pm 0.4 \%$, and the 3 rd group $12.3 \pm 0.2 \%$, respectively.

Thus, after a comprehensive examination with the identification of risk factors for cardiovascular events and subsequent calculation of CVR, after a course of treatment, there was a tendency to decrease this indicator. However, in 12 months of treatment and follow-up, new episodes of CVE were recorded, which unfortunately could not be prevented. Therefore, patients of all study groups were provided with further treatment recommendations and advice on continuing lifestyle modifications followed by follow-up.

\section{DISCUSSION}

Even though many medical instruments help to individually assess the CVR in a 10-year period, covering several clinical and laboratory data of the patient, they remain quite rough instruments [16-18]. However, CVR scales do not include other equally important RF that may directly affect the CVE prognosis over a 10-year period [19]. Treatment recommendations are based on data from the CVR, are group character that can reduce the effectiveness of individual therapy.

Therefore, more individualized scales for assessing CVR are currently being developed. Future CVR scales on the way to personalized medicine may take into account individual genetic characteristics, which will significantly increase their sensitivity. New and individual CVR assessment scales may lead to a rethinking of treatment guidelines and significantly improve treatment outcomes.

\section{CONCLUSIONS}

Patients with T2DM and concomitant obesity have higher CVR rates compared with groups of patients with T2DM and obesity alone. It is also important that in the long run, in 10 years or more, the indicators of CVR can be corrected, which reduces the risk of the patient having unwanted CVE and potential disability of the patient.

The frequency of CVE can be reduced by providing patients with adequate comprehensive treatment and control of blood pressure and hydrocarbon metabolism, lifestyle modifications, and the like. However, new cardiovascular events may occur due to unmodified risk factors and/or insufficient exposure to modified risk factors. 


\section{REFERENCES}

1. Naranjo C., Ortega-Jiménez P., Del Reguero L. et al. Relationship between diabetic neuropathic pain and comorbidity. Their impact on pain intensity, diabetes complications and quality of life in patients with type-2 diabetes mellitus. Diabetes research and clinical practice. 2020;165: 108236.

2. Poznyak A., Grechko A.V., Poggio A. et al. The diabetes mellitusatherosclerosis connection: The role of lipid and glucose metabolism and chronic inflammation. International journal of molecular sciences 2020; 21(5): 1835.

3. Demirdogen R.E. Relationship among blood boron level, diabetes mellitus, lipid metabolism, bone metabolism and obesity: Can boron be an efficient indicator for metabolic diseases. Health Sci. J. 2020;14, $1-11$.

4. Cole J.B., Florez J.C. Genetics of diabetes mellitus and diabetes complications. Nature Reviews Nephrology. 2020; 16(7): 377-390.

5. Faselis C., Katsimardou A., Imprialos K. et al. Microvascular complications of type 2 diabetes mellitus. Current vascular pharmacology. 2020; 18(2): 117-124.

6. Viigimaa M., Sachinidis A., Toumpourleka M. et al. Macrovascular complications of type 2 diabetes mellitus. Current vascular pharmacology. 2020; 18(2): 110-116.

7. Silveira E.A., de Souza Rosa L.P., de Souza Cardoso C.K. Type 2 diabetes mellitus in class II and III obesity: Prevalence, associated factors, and correlation between glycemic parameters and body mass index. International Journal of Environmental Research and Public Health. 2020; 17(11): 3930.

8. Blüher M. Obesity: global epidemiology and pathogenesis. Nature Reviews Endocrinology. 2019; 15(5): 288-298.

9. Choi J.R., Ahn S.V., Kim J.Y. et al. Comparison of various anthropometric indices for the identification of a predictor of incident hypertension: the ARIRANG study. Journal of human hypertension. 2018; 32(4): 294-300.

10. Siren R., Eriksson J.G., Vanhanen H. Waist circumference a good indicator of future risk for type 2 diabetes and cardiovascular disease. BMC public health. 2012; 12(1): 1-6.

11. Ohishi M. Hypertension with diabetes mellitus: physiology and pathology. Hypertension research. 2018; 41(6): 389-393.

12. Aggarwal P., Sinha S.K., Khanra D. et al. Comparison of original and modified $Q$ risk 2 risk score with Framingham risk score-An Indian perspective. Indian Heart Journal. 2021. doi: 10.1016/j.ihj.2021.01.016.

13. Romanens M., Szucs T., Sudano I. et al. Agreement of PROCAM and SCORE to assess cardiovascular risk in two different low risk European populations. Preventive medicine reports. 2019; 13: 113-117.

14. Santos A.S., Rodrigues A.P.S., Rosa L.P. et al. Cardiometabolic risk factors and Framingham Risk Score in severely obese patients: Baseline data from DieTBra trial. Nutrition, Metabolism and Cardiovascular Diseases. 2020; 30(3):474-482.

15. Goff D.C., Lloyd-Jones D.M., Bennett G. et al. 2013 ACC/AHA guideline on the assessment of cardiovascular risk: a report of the American College of Cardiology/American Heart Association Task Force on Practice Guidelines. Journal of the American College of Cardiology. 2014; 129(25): 49-73.
16. Khanna N.N., Jamthikar A.D., Gupta D. et al. Performance evaluation of 10-year ultrasound image-based stroke/cardiovascular (CV) risk calculator by comparing against ten conventional $\mathrm{CV}$ risk calculators: a diabetic study. Computers in biology and medicine. 2019; 105, 125-143.

17. American College of Cardiology/American Heart Association Guideline on the Assessment of Cardiovascular Risk (ASCVD Risk). 2013. http:// tools.acc.org/ASCVD-Risk-Estimator-Plus/\#!/calculate/estimate/.

18. Sohn C., Kim J., BaeW. The framingham risk score, diet, and inflammatory markers in Korean men with metabolic syndrome. Nutrition research and practice. 2012; 6(3): 246-253.

19. Paiter J., Oliveira G.M.M.D. Risk Prediction Systems: One for all or all for Some. International Journal of Cardiovascular Sciences. 2021; 34(1): 39-43.

20. Khera R., Valero-Elizondo J., Nasir K. Financial toxicity in atherosclerotic cardiovascular disease in the United States: current state and future directions. Journal of the American Heart Association. 2020; 9(19): doi: 10.1161/JAHA.120.017793.

The work was carried out in accordance with the plan of the research program of the Department of Therapy and Family Medicine of the Faculty of Postgraduate Education and Pre-University Training of Uzhhorod National University "Optimization of prevention and treatment of obesity and diabetes mellitus and Helicobacter", where the authors are co-authors.

\section{ORCID and contributionship:}

Taras I. Griadil: 0000-0002-1048-0656 ${ }^{A, B, C, D, E, F}$

Ivan V. Chopey: 0000-0003-4626-0855 A,B,C,D

Ksenia I. Chubirko: 0000-0002-4379-0538 C,D,E,F

Mykhaylo M. Hechko: 0000-0003-2793-5044 E,F

Wael Rumaneh: 0000-0001-7860-9674 C,E

\section{Conflict of Interest:}

The Authors declare no conflict of interest.

\section{CORRESPONDING AUTHOR}

\section{Taras I. Griadil}

Uzhhorod National University

148 Sobranetska st., 88017 Uzhhorod, Ukraine

tel: +380990080218

e-mail: taras.griadil@uzhnu.edu.ua

Received: 12.11 .2020

Accepted: 03.03 .2021

A - Work concept and design, B - Data collection and analysis, C - Responsibility for statistical analysis, D-Writing the article, $\mathbf{E}$-Critical review, $\mathbf{F}$ - Final approval of the article 